\title{
Ensuring attachment security in adolescents: as easy as $\mathrm{ABC}$ ?
}

\author{
By Jessica K. Edwards
}

Researchers in the USA have examined whether infants of parents receiving the Attachment and Biobehavioral Catch-Up ( $A B C$ ) intervention ${ }^{1}$ show improvements in perceived attachment security later in middle childhood. The longitudinal, randomized clinical trial involved 100 children who had been referred to Child Protective Services due to their high risk of maltreatment. The children and their parents were randomly assigned to receive either the $A B C$ intervention or a control intervention (Developmental Education for Families) during infancy and then followup was made at age 9 years. The children of parents who received $A B C$ showed a higher level of attachment security at age 9 years than the children of parents who received the control intervention. Intervening early to promote caregiving quality might, therefore, have longterm effects. The researchers explain that this brief intervention comprising 10, hour-long sessions might be able to promote attachment security over a long period in children at risk of maltreatment. Further work is now needed to determine the potential mediators of ABC's effect on attachment security in middle childhood and whether these effects of $A B C$ on long-term attachment security are demonstrated in other high-risk samples.

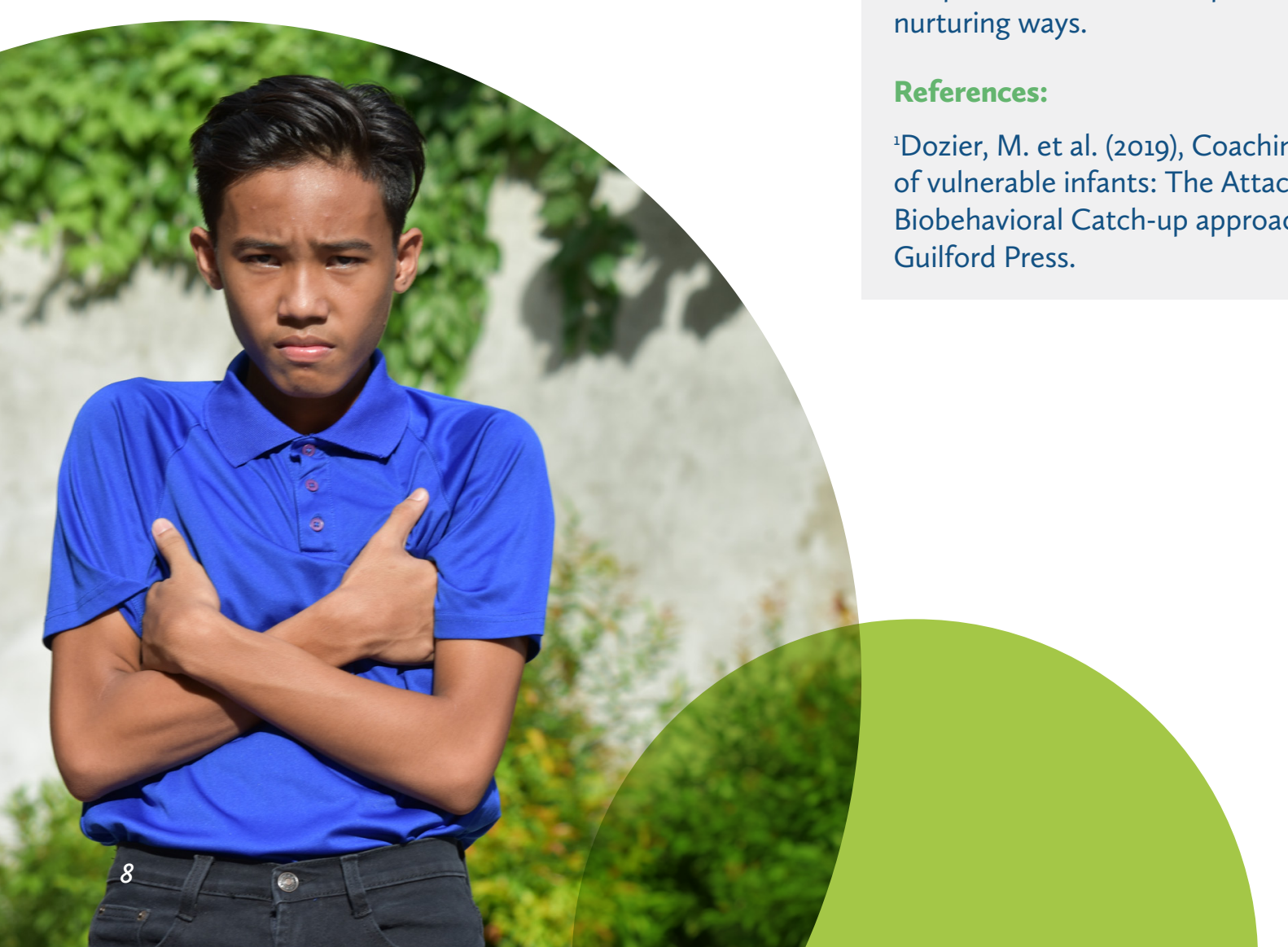

\begin{abstract}
Referring to:
Zajac, L., Raby, K.L. \& Dozier, M. (2019), Sustained effects on attachment security in middle childhood: Results from a randomized clinical trial of the Attachment and Biobehavioral Catchup (ABC). J. Child Psychol. Psychiatr. doi: 10.111/ jcpp.13146.
\end{abstract}

\section{See also:}

Trial name: Intervening Early with Neglected Children. Registry ID: NCT02093052. https://clinicaltrials.gov/ct2/show/ NCT02093052?term=dozier\&rank=1

\section{Glossary:}

\section{Attachment and Biobehavioral Catch-Up} $(A B C): A B C$ aims to improve caregiving quality by helping parents provide nurturance when children are distressed, respond in sensitive ways when children are not distressed, and reduce frightening or harsh behaviours. $A B C$ is conducted in the family home and consist of 10 , 1-hour long sessions. Across all sessions, "parent coaches" provide instant feedback to reinforce target behaviours, identify examples, and support the parents' efforts to respond in sensitive and nurturing ways.

\section{References:}

Dozier, M. et al. (2019), Coaching parents of vulnerable infants: The Attachment and Biobehavioral Catch-up approach. New York: Guilford Press. 